\title{
Dilemma of One Common Central Bank in a Heterogeneous Monetary Union
}

\author{
Séverine Menguy \\ Université de Paris X-Nanterre
}

\begin{abstract}
The paper studies the appropriate weight that the central bank of a heterogeneous monetary union should give to each specific country. To stabilize symmetric shocks, the central bank should give a bigger weight to the countries where the rigidity in the labor market and the sensibility of the demand to the interest rate are the highest, whereas equally weighting each country is justified for asymmetric shocks. Moreover, the central bank should overweight the country which has a smaller preference for sustaining the economic activity and a higher preference for stabilizing public expenditures.
\end{abstract}

- JEL Classification : E52, E63

- Key Words: monetary policy, monetary union, structural heterogeneity, heterogeneity in preferences

\section{Introduction}

In its statutes, the European Central Bank (ECB) is held responsible, from an institutional point of view, for the average performance of the entire Eurozone. So, the official view on ECB monetary policy claims that monetary decisions are based solely on average data for the Eurozone, letting national idiosyncrasies to the care of national governments. The primary objective of the ECB is the maintenance of price stability (art. 105), and to this aim, it should be politically independent (art.

\footnotetext{
*Corresponding address: Séverine Menguy: EconomiX. Université de Paris X-Nanterre, bâtiment K, 200 Avenue de la République, 92001 Nanterre Cedex, France. Tel: (00 33) 1409759 14, e-mail: menguy.severine@wanadoo.fr 
107). Concerning the potentiality of an activist monetary policy taking into account the particular development of specific countries, Issing (2004) said: "I see enormous problems with the implementation of such a policy. How would we make sure that, by assigning a higher importance/weight to some country or sectorspecific developments, we would not actually reward behavioral or structural inefficiencies, ultimately creating perverse incentives and even hampering the necessary progress towards more market-based adjustment mechanisms? How much confidence do we have on the precise estimates of the differential impact of monetary policy on different sectors or countries? What would the trade-off be in terms of a higher volatility of inflation and output at the aggregate level? Would the complexity of our policy not rise to such a level that it would become extremely difficult to explain our actions to the public?"

Nevertheless, the differences inmonetary policy transmissionmechanisms may hamper themonetary policy decisions-making of the ECB, andmodify and change the monetary policy in the Economic and Monetary Union (EMU). Indeed, the European Union was created to serve the interests of its member states; it is not a nation state which has a federal organization. The Governors in the Governing Council have as mandate to represent the interest of the EMU member states as a whole. But the national interests have still a non negligible weight, especially when economic conditions and/or structural parameters diverge systematically between the countries. Furthermore, empirically, the ECB uses national information : it uses a multi-country approach to the econometric modelling of the Euro area, the national and econometric models managed by the national central banks have a prominent role in the forecasting framework, and the national information is available earlier than area statistics computed by Eurostat. In this framework, the conduct of monetary policy in the Eurozone is quite diffi-cult because of three kinds of heterogeneities: a) between the shocks hitting the European economies; b) between the transmission mechanisms of these shocks and of the economic policies in the monetary union; c) between the preferences of the European governments. Whereas the first heterogeneity, the asymmetry in the shocks, has been widely studied in the literature, the other points of interest, the structural heterogeneity and the conflict of goals between the member countries of a monetary union, have perhaps been less often analyzed. Indeed, most papers and macroeconomic studies regarding the policy-mix in a monetary union assume that its member countries are fully identical. However, even if the empirical studies about these heterogeneities are quite scarce, the enlargement of the EMU will 
probably tend to increase these heterogeneities.

The aim of the present paper is thus to study the consequences of the heterogeneities between the countries of a monetary union on the monetary policy of a common central bank. The section II mentions some papers which have already tried to investigate the consequences of such heterogeneities on the policymix in a monetary union, a concern still underdeveloped in the economic literature. The section III describes a rather simplified analytical model, however well adapted to our goal, which takes into account the discrepancies between the member countries of a monetary union. The section IV determines the economic policies and the Nash equilibriumof ourmodel. The section V studies the consequences of the structural heterogeneities between the member countries of a monetary union, and the section VI those between their preferences. Finally, the section VII concludes the paper.

\section{Overview of the Economic Literature}

Up until now, the theoretical literature on the optimal monetary policy within a monetary union has shown that the structural heterogeneities between the member countries probably call for the design of a monetary policy that takes into account national data, and not only average and euro-aggregate data (see for example: De Grauwe and Senegas, 2004). From an empirical viewpoint, Heine-mann and Hüfner (2004) show that conventional Taylor rules that rely solely on Eurozone variables might be biased. The econometric estimations show that for inflation considerations, in particular, the ECB empirically also considers regional data, even if the importance of national output data is less evident. Indeed, De Grauwe (2000), Angelini et al. (2002) or Jondeau and Sahuc (2006) find that targeting national variables may deliver large welfare gains. More precisely, Angelini et al. (2002) show that the central bank should have a reaction function responding to national developments, even if its objectives and its loss function are framed in area-wide terms. But Jondeau and Sahuc (2006) show that it isn't the use of a rule based on aggregate variables that is costly in terms of welfare; it is rather the use of a suboptimal forecasting model. However, using a dynamic macroeconomic model, De Grauwe and Piskorski (2001) moderate this conclusion on the utility of considering national data. Indeed, the authors show that the policy based on the union-wide aggregates yields stabilization performances that are quite close to the policy based on the national data of the member states. Therefore, the aggregate 
data targeting may provide a better framework for the conduct of monetary policy by being simpler and by denationalizing the key decision variables, limiting the potential conflict of goals between countries.

Regarding the implications of the structural heterogeneities on the stabilization of different kinds of shocks, Gregoriadis et al. (2006) try to define analytically the consequences of the heterogeneity in the transmission mechanisms of mon-etary policy for the conduct of that policy in a monetary union. In the same way, Gros and Hefeker (2002) show that a central bank that cares about national variables usually provides less stabilization of common shocks. Nevertheless, according to the authors, a single country could gain from a central bank that cares about unionwide variables if its transmission mechanisms are close to the average, and if the corresponding parameters are not excessively high or low in that country. Next, according to Brissimis and Skotida (2007), there are gains to be achieved by the central bank taking into account the heterogeneity of economic structures, for example in price and wage-setting mechanisms and in consumption behavior patterns. More precisely, the central bank must react more aggressively to the macroeconomic developments in the country with a steeper Phillips curve and/or a lower inter-temporal elasticity of substitution of consumption, i.e. a steeper aggregate demand curve. Indeed, because of these higher sensibilities, the central bank must react more aggressively to stabilize this country's variables. To the contrary, reacting strongly to shocks in less responsive countries would imply too important variations in the interest rate and in the economic variables in the more responsive country. Similar results are found in De Grauwe and Piskorski (2001) and Angelini et al. (2002).

Aksoy et al. (2002) also use a model where asymmetric shocks and divergent propagation of shocks in output and inflation are potential causes of tensions within the ECB concerning the conduct of a common monetary policy. Then, they show that the frustration of the small countries regarding the decisions taken in Frankfurt increases with the desire of their governments to stabilize output. In the same line of inquiry, but with a dynamic model, Penot (2004) tries to define the consequences of the integration of the Euro area heterogeneity into the loss function of the central bank. He finds that reducing the gap between the Euro area countries is associated with worse performances in terms of aggregate objectives. So, the ECB would face a trade-off between the reduction of national dispersion and aggregate stabilization. Finally, Brissimis and Skotida (2007) show that the loss due to the use of union-wide variables increases in proportion to the relative 
importance that the central bank attaches to the goals of output gap and interest rate stabilization compared to inflation stabilization. Indeed, this weakens inflation targeting and increases welfare losses.

This paper is therefore in the tradition of these studies which attempt to identify the implications of the structural heterogeneity between the member countries of a monetary union on the conduct of the common monetary policy. Thus, we need an analytical model of monetary union where the transmission of monetary policy but also other parameters are asymmetric. In that framework, should the ECB minimize a loss function whose arguments are aggregates covering the whole Eurozone, or a weighted sum of national loss functions? The necessity to take into account national data in a heterogeneous monetary union has already been shown in the above mentioned literature. But beyond this re-sult, the present paper aims at defining the right weight that the ECB should give to each particular country in its loss function, according to the nature of the shocks that must be stabilized and to the heterogeneities at stake. So, the contribution of this paper is to determine the optimal weight that the common central bank of a monetary union should give to the member countries according to their various structures or preferences.

\section{Description of the Model}

The main limit associated with most former studies on the stabilization of shocks in a monetary union is that they often suppose that the member countries are completely identical. On the contrary, the present paper focuses on the structural heterogeneities between the member countries of a monetary union, and on the discrepancies between their preferences, the other aspects of our model being quite traditional and simplified. We use a simple static model of a closed monetary union with two heterogeneous countries facing symmetrical or asymmetrical supply or demand shocks. Monetary policy is determined by the common central bank, whereas fiscal policies are set by the decentralized governments at the national level. In a short run perspective, we avoid here the problems related to the increase in deficits implied by the budgetary policy. We also avoid the problems due to the possible inflationary monetary financing of the public debt, empirically slight in Europe and institutionally forbidden by the Maastricht Treaty today. By considering a closed monetary union, we avoid the problems related to the relationships with the rest of the world too. All the variables are expressed in log-deviations from their long run equilibrium values, 
except the interest rate; all expected quantities are therefore set to zero. In the short run, prices as well as production can temporarily deviate from their equilibrium levels. Contrary to De Grauwe (2000), De Grauwe and Senegas (2004) or Gros and Hefeker (2000) for example, we do not suppose that inflation is the same in all member countries of a monetary union. First, inflation differentials are more in conformity with the empirical reality in the EMU. Indeed, the empirical literature tends mostly to show the persistence of quite large inflation differentials between the European countries. ${ }^{1}$ The enlargement of the EMU should also rather increase the size of the inflation and output divergences, as the new members' relatively low levels of economic development imply temporarily higher than average inflation and growth rates (Balassa-Samuelson effect). Taking into account inflation divergences is also necessary from a theoretical viewpoint to study the weight that the central bank should give to these differentials in its loss function; it is absolutely necessary to deal with the subject of the present paper. That is why we suppose that the central bank cannot control and minimize the level of inflation, which differs between the member countries of the monetary union. Instead, we make the hypothesis that the central bank only controls the interest rate $(r)$.

\section{A. The Framework}

First, we use a simple "Lucas output supply function":

$$
y_{i}^{s}=a_{i} \pi_{i}+s_{i}
$$

with $\left(y_{i}\right)$ : production in the country (i); $\left(\pi_{i}\right)$ : inflation in the country (i); $\left(s_{i}\right)$ : asymmetric supply shock, whose variance is $\sigma_{s i}^{2}$. These shocks are supposed to be white noises, pure national shocks independently distributed. On the contrary, $(s)$ is a symmetric supply shock, whose variance is $\sigma_{s}^{2}$; we also assume that it is not correlated with the national shocks. Finally, $a_{i}>0$.

Thus, in this function, production can deviate from its natural (null) level because of a productivity supply shock, or because of a surprise (unanticipated) inflation. In this framework, logically, the higher the rigidity (resp. flexibility) in the labor market in the country $(i)$, the more inertial the economy is, and the higher (resp. weaker) are the output loss necessary to a disinflationary economic policy and the parameter $\left(a_{i}\right)$.

Then, we introduce a very simple demand function in order not to complicate

${ }^{1}$ See for example Issing (2004) and the papers presented at the ECB Workshop on 13/14 December 2004. 
the model excessively:

$$
y_{i}^{d}=g_{i}-\sigma_{i} \cdot r+b_{i} \cdot\left(\pi_{j}-\pi_{i}\right)+d_{i}
$$

with $\left(g_{i}\right)$ : public expenditures in the country $(i) ;(r)$ : interest rate in the monetary union; $\left(d_{i}\right)$ : asymmetric demand shock, whose variance is $\sigma_{d i}^{2}$. These shocks are supposed to be white noises, pure national shocks independently distributed. On the contrary, $(d)$ is a symmetric demand shock, whose variance is $\sigma_{d}^{2}$; we also assume that it is not correlated with the national shocks. Furthermore, $\left(\sigma_{i}\right)>0$ and $\left(b_{i}\right)>0$.

So, the demand in a country $(i)$ is an increasing function of the public expenditures and of a positive demand shock in this country, and a decreasing function of the common interest rate. Moreover, the exports are an increasing function of the price competitiveness of the country.

Finally, the monetary union consists of two countries: $(i)$ and $(j)$. For each parameter $(x)$, we suppose that: $x_{i}=\left(1-h_{x}\right) \mathrm{x}$ and $x_{j}=\left(1+h_{x}\right) x$, where $x$ is the average value of the parameter. So, the degree of heterogeneity in the parameter $(x)$ is $\left(h_{x}^{2}\right)$ with: $0<h_{x}^{2}<1$. In this framework, each variable or parameter $(x)$ has an average or symmetric component: $x=1 / 2\left(x_{i}+x_{j}\right)$, and a differential or asymmetric component: $\bar{x}=1 / 2\left(x_{i}-x_{j}\right)$. We suppose that these components are independently distributed and that the covariance between them is null.

By combining these equations, we may find the formal expressions of the inflation and activity levels (see Appendix 1). ${ }^{2}$ For $x_{i}=y_{i}$ or $\pi_{i}$, we have:

$$
x_{i}=a_{x i, d}(g+d)+a_{x i, \bar{d}}(\bar{g}+\bar{d})+a_{x i, r} r+a_{x i, s} s+a_{x i, \bar{s}} \bar{s}
$$

Indeed, it has already been shown (see: Asensio, 2006; Barbier Gauchard and Blot, 2004) that if there are structural heterogeneities between the member countries of a monetary union, the average economic variables are a function of the average economic policies and of the symmetric shocks, but also of the differential between the budgetary policies and of the asymmetric shocks. Monetary, budgetary and fiscal instruments respond to every type of shocks in a heterogeneous system. ${ }^{3}$

\footnotetext{
${ }^{2}$ In Hughes-Hallett and Weymark (2001), the formal determination of the basic equations of the model is much easier, because they ignore potential spillover effects among countries.

${ }^{3}$ With the help of simulations, Asensio (2006) shows that in case of heterogeneity, monetary policy could specialize in countering the common effect of shocks, while governments would concentrate in countering the idiosyncratic effects. He suggests thus an application of the subsidiarity principle to the macroeconomic governance of the Eurozone.
} 
In order to study precisely the effect of different kinds of heterogeneities on the optimal policy-mix in a monetary union, we must however precise the loss functions of the economic authorities.

\section{B. The Loss Functions}

As in De Grauwe and Senegas (2004), Gros and Hefeker (2000) or Gregoriadis et al. (2006), we make two hypotheses regarding the setting of a single monetary policy in a monetary union. First, the common central bank can use information about national unemployment and inflation levels, and minimize an average of national losses. So, it minimizes:

$$
L_{N}^{M}=\frac{1}{4}\left(\pi_{i}^{2}+\pi_{j}^{2}+\gamma^{M} \cdot y_{i}^{2}+\gamma^{M} \cdot y_{j}^{2}\right)
$$

where $(\gamma M)$ denotes the weight accorded to the economic activity goal by the central bank, relative to the weight given to the price stability goal normalized to unity. For convenience, given the statutes of the European Central Bank, the target for inflation can be set equal to zero. Moreover, like De Grauwe and Piskorski (2001) for example, we also suppose that the target for output is null (its natural level). Indeed, it is implausible that the central bank systematically pursues an output objective that exceeds the natural level of output, even if the current activity is below the level that would allow full employment. Moreover, we want to study the stabilization policies in a monetary union, whereas the inflation bias due to the desire to target a higher economic activity level than its natural level is a distinct question.

On the contrary, the central bank can choose to stick to union-wide aggregate variables and to minimize a welfare function using only average variables, weighted averages of national inflation rates and levels of economic activity. Then, it minimizes:

$$
L_{A}^{M}=\frac{1}{2}\left[\left(\mu_{i} \cdot \pi_{i}+\mu_{j} \cdot \pi_{j}\right)^{2}+\gamma^{M} \cdot\left(\mu_{i} \cdot y_{i}+\mu_{j} \cdot y_{j}\right)^{2}\right]
$$

where $(\mu k)$ with $\kappa \varepsilon\{i, j\}$ is the weight given to the country $(k)$ by the central bank when computing average variables, and with: $\mu_{i}+\mu_{j}=1$. Let us mention that the weight given to a country in the decision-making process may or may not be related to the economic weight or to the population of this country.

Finally, the loss function of each country $(k)$ of the monetary union is: 


$$
L_{k}^{G}=\frac{1}{2}\left(\pi_{k}^{2}+\gamma_{k}^{G} \cdot y_{k}^{2}+\xi_{k}^{G} \cdot g_{k}^{2}\right)
$$

where $\left(\gamma_{k}^{G}\right)$ denotes the weight accorded to the economic activity goal and $\left(\xi_{k}^{G}\right)$ the weight accorded to stabilizing public expenditures by the country $(k)$, relative to the weight given to the price stability goal normalized to unity.

So, like the central bank, each country is endowed with a social loss function that depends on deviations of income and inflation from their equilibrium levels. We also suppose that the governments try to reduce the variations in their public expenditures, as their budgetary policies are constrained in Europe by the Stability and Growth Pact. ${ }^{4}$ Besides, we study not only the case of a structural heterogeneity, but also the case where there is a heterogeneity in the preferences of the governments and potential preference conflicts between the member countries of the monetary union. We also suppose that the most important is not the union-wide welfare. Instead, we want to insist on the welfare of the society in each particular country, which is supposed to be inversely proportional to the expected value of the loss function in each country $(k)$ : $E\left(L_{k}^{G}\right)$, where $E$ denotes the rational expectations operator.

\section{Determination of the Economic Policies}

In this paper, we study only the non-cooperative equilibrium of our model. Indeed, the ECOFIN Council and the Euro-group have only introduced a weak cooperation between the European governments. The cooperative equilibrium thusdoesn't seem to fit to the European framework. Moreover, the question of the necessity of the cooperation between the governments in a heterogeneous monetary union has already been studied in the literature (see for example: BarbierGauchard and Blot, 2004). Regarding the nature of the policy game between the economic authorities, they are supposed to play simultaneously. ${ }^{5}$

\footnotetext{
${ }^{4}$ We suppose that the governments try to limit the variations in their public expenditures, falling because of the political necessity to maintain the supply of a certain level of public goods and services, and rising because of the necessity to avoid aggravating the public deficits.

${ }^{5}$ Grimm and Ried (2007) show that welfare losses are significantly larger in a heterogeneous union, and all the more as the regions are asymmetric. Nevertheless, they also demonstrate that these losses could be reduced by a first mover advantage of monetary policy.

${ }^{6}$ This precise modelling of the behavior of the governments is one of the specific contribution of our paper, in comparison with Gregoriadis et al. (2006), for example.
} 


\section{A. Reaction Function of the Governments}

Without any cooperation, the budgetary policy decided by the government of the country $(i)$, and then $g$ and $\bar{g}$, are (see Appendix 2$)^{6}$ :

$$
\begin{gathered}
h_{0}(d) \cdot g_{i}=2 h_{2, i}(r) \cdot r+2 h_{2, i}(d) \cdot d+2 h_{2, i}(\bar{d}) \cdot \bar{d}+2 h_{2, i}(s) \cdot s+2 h_{2, i}(\bar{s}) \cdot \bar{s} \\
h_{0}(d) \cdot g=-h_{4}(r) \cdot r-h_{4}(d) \cdot d-h_{4}(\bar{d}) \cdot \bar{d}-h_{4}(s) \cdot s-h_{4}(\bar{s}) \cdot \bar{s} \\
h_{0}(d) \cdot \bar{g}=h_{3}(r) \cdot r+h_{3}(d) \cdot d+h_{3}(\bar{d}) \cdot \bar{d}+h_{3}(s) \cdot s+h(\bar{s}) \cdot \bar{s} \\
h_{0}(d)=h_{1}(\bar{d}, d)+2 \xi_{i}^{G}\left(\alpha_{\pi j, d 3}^{2}+\gamma_{j}^{G} \alpha_{y j, d 3}^{2}\right)+2 \xi_{i}^{G}\left(\alpha_{\pi i, d 2}^{2}+\gamma_{i}^{G} \alpha_{y j, d 2}^{2}\right)+2 \xi_{i}^{G} \xi_{j}^{G} \\
h_{1}\left(z_{1}, z_{2}\right)=\alpha_{\pi i, d 2} \alpha_{\pi j, d 3}\left(\alpha_{\pi j, z 2} \alpha_{\pi i, z 1}-\alpha_{\pi i, z 2} \alpha_{\pi j, z 1}\right)+\gamma_{i}^{G} \alpha_{y i, d 2} \alpha_{\pi j, d 3}\left(\alpha_{\pi j, z 2} \alpha_{y i, z 1}\right. \\
\left.-\alpha_{y i, z 2} \alpha_{\pi j, z 1}\right)+\gamma_{j}^{G} \alpha_{\pi i, d 2} \alpha_{y j, d 3}\left(\alpha_{y j, z 2} \alpha_{\pi i, z 1}-\alpha_{\pi i, z 2} \alpha_{y j, z 1}\right)+\gamma_{i}^{G} \gamma_{j}^{G} \alpha_{y i, d 2} \alpha_{y i, d 3} \\
\left(\alpha_{y j, z 2} \alpha_{y i, z 1}-\alpha_{y i, z 2} \alpha_{y j, z 1}\right) \\
h_{2, i}(z)=h_{1}(d 3, z)-\xi_{j}^{G}\left(\alpha_{\pi i, d 2} \alpha_{\pi i, z}+\gamma_{i}^{G} \alpha_{\pi i, d 2} \alpha_{\pi i, z}+\gamma_{i}^{G} \alpha_{y i, d 2} \alpha_{y i, z}\right) \\
h_{3}(z)=h_{1}(d, z)+\xi_{i}^{G}\left(\alpha_{\pi j, d 3} \alpha_{\pi j, z}+\gamma_{j}^{G} \alpha_{y i, d 3} \alpha_{y i, d 3}\right)-\xi_{i}^{G}\left(\alpha_{\pi i, d 2} \alpha_{\pi i, z}+\gamma_{j}^{G} \alpha_{y i, d 2} \alpha_{y i, z}\right) \\
h_{4}(z)=h_{1}(\bar{d}, z)+\xi_{i}^{G}\left(\alpha_{\pi j, d 3} \alpha_{\pi j, z}+\gamma_{j}^{G} \alpha_{y j, d 3} \alpha_{y j, z}\right)+\xi_{i}^{G}\left(\alpha_{\pi i, d 2} \alpha_{\pi i, z}+\gamma_{j}^{G} \alpha_{y i, d 2} \alpha_{y i, z}\right) \\
\text { with: } \alpha_{x i, d 2}=1 / 2\left(\alpha_{x i, d}+\alpha_{x i, \bar{d}}\right) \text { and } \alpha_{x i, d 3}=1 / 2\left(\alpha_{x i, d}-\alpha_{x i, \bar{d}}\right) \cdot
\end{gathered}
$$

Proposition 1: If and only if the member countries of the monetary union are identical, the global budgetary policy responds to symmetric shocks whereas the differential in budgetary policies responds to asymmetric shocks.

Proof: Without structural heterogeneity between the member countries, $\alpha_{x i, z}=-\alpha_{x j, z}$ and $\alpha_{x i, z}=\alpha_{x j, z}(\forall z)$, and then also $\alpha_{x i, d 2}=\alpha_{x j, d 3}$. Moreover, $\alpha_{y i, s}=\alpha_{y j, s}=0$. Thus, if the preferences of the governments are identical: $h_{4}(\bar{d})=h_{4}(\bar{s})=h_{3}(d)=h_{3}(r)=h_{3}(s)=0$.

\section{B. Reaction Function of the Central Bank}

For $z=(g+d),(\bar{g}+\bar{d}), s$ or $\bar{s}$, if the central bank takes into account information about national variables $(N)$, with equation (4), the interest rate which verifies $\frac{d L_{N}^{M}}{d r}=0$ is:

$$
\left(\alpha_{\pi i, r}^{2}+\alpha_{\pi j, r}^{2}+\gamma^{M} \alpha_{y i, r}^{2}+\gamma^{M} \alpha_{y j, r}^{2}\right) r_{N}
$$




$$
=-\sum_{z}\left(\alpha_{\pi i, r} \alpha_{\pi i, z}+\alpha_{\pi j, r} \alpha_{\pi j, z}+\gamma^{M} \alpha_{y i, r} \alpha_{y i, z}+\gamma^{M} \alpha_{y j, r} \alpha_{y j, z}\right) z
$$

On the contrary, if it only considers aggregate average variables $(A)$, with equation(5), it fixes the interest rate at the level which verifies:

$$
\begin{aligned}
\frac{d L_{A}^{M}}{d r} & =0 \text { that is to say: }\left[\left(\mu_{i} \alpha_{\pi i, r}+\mu_{j} \alpha_{\pi j, r}\right)^{2}+\gamma^{\mathrm{M}}\left(\mu_{i} \alpha_{y i, r}+\mu_{j} \alpha_{y j, r}\right)^{2}\right] r_{A} \\
& =\sum_{z}\left[\left(\mu_{i} \alpha_{\pi i, r}+\mu_{j} \alpha_{\pi j, r}\right)\left(\mu_{i} \alpha_{\pi i, z}+\mu_{j} \alpha_{\pi j, z}\right)+\gamma^{M}\left(\mu_{i} \alpha_{y i, r}+\mu_{j} \alpha_{y j, r}\right)\left(\mu_{i} \alpha_{y i, z}+\mu_{j} \alpha_{y j, z}\right)\right] z
\end{aligned}
$$

Proposition 2: Without structural heterogeneity between the member countries of the monetary union, taking into account national information, or using averages variables and granting the same weight to each country in the calculation of aggregate variables; all this leads to the same decision for the central bank. In that case, the common central bank however only reacts to average data.

Proof: Without structural heterogeneity, (10) and (11) are similar if $\mu_{i}=\mu_{j}=1 / 2$. Moreover, $\alpha_{x i, \bar{z}}=-\alpha_{x j, \bar{z}}$ and $\alpha_{x i, z}=\alpha_{x j, z}(\forall z)$.

\section{Determination of the Nash Equilibrium}

We can now determine the policy-mix between the economic authorities. As in Hughes Hallett and Weymark (2001) or Asensio (2006), for example, we suppose that the game between the economic authorities is a Nash equilibrium, and that the authorities play simultaneously. By combining the former reaction functions of the economic authorities: (8), (9) and $r=\alpha_{r, d}(g+d)+\alpha_{r, \bar{d}}(\bar{g}+\bar{d})+\alpha_{r, s} s+\alpha_{r, \bar{s}} \bar{s}(10 / 11)$, we obtain, for $z=d, \bar{d}, \bar{s}$ or $\bar{s}$ :

$$
\begin{gathered}
h_{5}(d, \bar{d}, r) \cdot r=\sum_{z}\left[\alpha_{r, z} h_{0}(d)+\alpha_{r, \bar{d}} h_{3}(z)-\alpha_{r, d} h_{4}(z)\right] z \\
h_{5}(d, \bar{d}, r) \cdot g=-\sum_{z}\left[\alpha_{r, z} h_{4}(r)+h_{4}(z)-\alpha_{r, \bar{d}} h_{6}(z)\right] z \\
h_{5}(d, \bar{d}, r) \cdot \bar{g}=\sum_{z}\left[\alpha_{r, z} h_{3}(r)+h_{3}(z)-\alpha_{r, d} h_{6}(z)\right] z
\end{gathered}
$$

with $h_{5}(d, \bar{d}, r)=\left[h_{0}(d)-\alpha_{r d}-h_{3}(r)+\alpha_{r d} h_{4}(r)\right] ; h_{6}(z)=\left[h_{4}(z) h_{3}(r)-h_{4}(r) h_{3}(z)\right] / h_{0}(d)$.

As the shocks are white noises and are independently distributed, for $z=d, \bar{d}, s$ or $\bar{s}$, the anticipated loss function for the country $(k)$ is as follows: 


$$
\begin{gathered}
E\left(L_{k}^{G}\right)=\frac{1}{2} E\left(\pi_{k 2}^{2}\right)+\frac{\gamma_{k}^{G}}{2} E\left(y_{k 2}^{2}\right)+\frac{\xi_{k}^{G}}{2} E\left(g_{k 2}^{2}\right) \\
=\sum_{z}\left[\frac{1}{2}\left(\alpha_{\pi k 2, z}^{2}\right)+\frac{\gamma_{k}^{G}}{2}\left(\alpha_{y k 2, z}^{2}\right)+\frac{\xi_{k}^{G}}{2}\left(\alpha_{g k 2, z}^{2}\right)\right] \operatorname{Var}(z)
\end{gathered}
$$

with, based on (3):

$$
\alpha_{x k 2, z}=a_{x k, d} \frac{d g}{d z}+a_{x k, \bar{d}} \frac{d \bar{g}}{d z}+a_{x k, r} \frac{d r}{d z}+a_{x k, z} \quad \text { for } \mathrm{x}_{k}=\pi_{k} \text { or } y_{k}
$$

We must now compare these loss functions according to the two different monetary policies of the central bank: whether it considers weighted average $(A)$ or national $(N)$ variables. Thus, we will calculate the percentage loss in the social well-being for the country $(k)$ due to the consideration of weighted average variables by the central bank in comparison with the observation of national decentralized information $\left(\Delta W_{k}\right)$. In order to evaluate the social loss due to the centralization $(A)$, for different kinds of heterogeneities, we will therefore estimate the following differential:

$$
\Delta W_{k}=\left[E\left(L_{k}^{G}\right)^{A}-E\left(L_{k}^{G}\right)^{N}\right] / E\left(L_{k}^{G}\right)^{N}
$$

\section{Consequences of the Structural Heterogeneity}

In this section, we will try to clarify what is the optimal monetary policy with structural heterogeneity between the member countries of a monetary union.

For this part, we will assume the following calibration: $\sigma=0.2, b=0.4, a=3$ (see Appendix 3), $\gamma^{\mathrm{M}}=0.5, \gamma_{i}^{G}=\gamma_{j}^{G}=2, \xi_{i}^{G}=\xi_{j}^{G}=0.5$

\section{A. Stabilization of Symmetric Shocks}

According to De Grauwe (2000), as the degree of asymmetries in the transmission mechanisms increases, the effectiveness of stabilization of output and unemployment is reduced. Therefore, the stabilization effort of the central bank declines and welfare decreases, especially in the less flexible country. Nevertheless, the central bank can improve the efficiency of its monetary policy by using national information in the setting of optimal policies. Gros and Hefeker (2000) also show, in a standard and static framework, that a central bank that focuses on 
appropriately weighted national rates of inflation and growth reacts less to common shocks than a central bank basing its decisions on EU-wide average variables. Indeed, it is then more cautious not to harm a particular country by its monetary policy when the countries have different needs for active monetary policy. In the same way, our model proves the traditional risk of over-stabilization of symmetric shocks due to centralization $(A)$ : monetary policy is more active when the central bank considers average variables.

Then, without structural heterogeneity, the central bank could fully stabilize symmetric demand shocks [ $r=5 d$ with our calibration]. Indeed, within our model, the central bank is not constrained in the variations in its instrument, unlike the governments. The variations in public expenditures, in inflation or in economic activity would then be null in both countries. In fact, the only structural heterogeneity which prevents the central bank from fully stabilizing the symmetric positive demand shocks is the heterogeneity between the sensibilities of demands to the interest rate $(\sigma)$. In that case, in our model, the stabilization becomes imperfect whatever the loss function of the central bank. Indeed, the budgetary policy is then expansionary in the country $(i)$ where the sensibility of the demand to the interest rate is the highest, in order to compensate for the more contractionary effect of the monetary policy. There is thus a conflict of goals between the central bank and the government of that country $(i)$, where there is a decrease in activity and a deflation. On the contrary, the country $(j)$ encounters inflation and economic growth, despite its restrictive budgetary policy. Moreover, if the transmission mechanisms of monetary policy are heterogeneous, the latter appears more restrictive when the central bank only considers average variables $(A)$. Our model also shows that considering average variables $(A)$ is moderately beneficial to the country $(j)$ where the sensibility is kept at the lowest level, whereas a less restrictive monetary policy and considering national variables $(N)$ is very beneficial to the country $(i)$ where the sensibility is the highest. The structural heterogeneity can thus imply a conflict of goals between the countries of a monetary union.

\footnotetext{
${ }^{7}$ The heterogeneity in the parameter $(\sigma)$ is the only one studied by Gregoriadis et al. (2006). In that case, the authors demonstrate that the inefficiency associated with a monetary policy considering only average variables can also be removed by the setting of an optimal contract for the central bank. In that contract, the penalties imposed on inflation (resp. output) divergences should be higher than the relative weight of inflation (resp. output) in the social loss function.
} 
Proposition 3: In case of symmetric demand shocks, the central bank of a heterogeneous monetary union can avoid leading an excessively active monetary policy if when computing average variables, it overweights the country where the sensibility of the demand to the interest rate is the highest.

Figure 1 gives the welfare differential $\Delta W_{i} / W_{i}$ (in \%) as a function of the structural heterogeneity $\left(h_{s}\right)$ for the country $(i)$ (the curves are exactly symmetric for the country $(j)$, the axis being $\left.h_{s}=0\right)$. So, we can see that the cost of centralization increases much with that heterogeneity for the country in which the sensibility $\sigma$ is the highest. ${ }^{7}$

Regarding the symmetric positive supply shocks, monetary policy is then expansionary ( $r=-3.35 s$ with identical countries) to reduce the deflation in both countries $\left(\pi_{i}=\pi_{j}=-0.27 \mathrm{~s}\right)$. The budgetary policies are thus restrictive $\left(g_{i}=g_{j}=-0.49 \mathrm{~s}\right)$ to compensate for the expansionary monetary policy, and to reduce the increase in economic activity $\left(y_{i}=y_{j}=0.18 \mathrm{~s}\right)$. There is therefore a conflict of goals between the

Figure 1. Loss Due to Centralization for $(i)$, Symmetric Demand Shock $(d)$

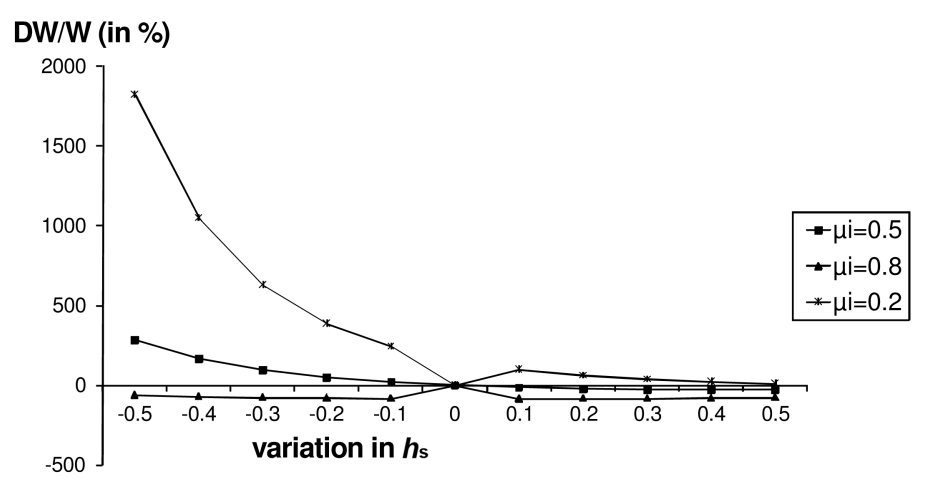

Figures 2. a,b. Loss Due to Centralization for $(i)$, Symmetric Supply Shock $(s)$
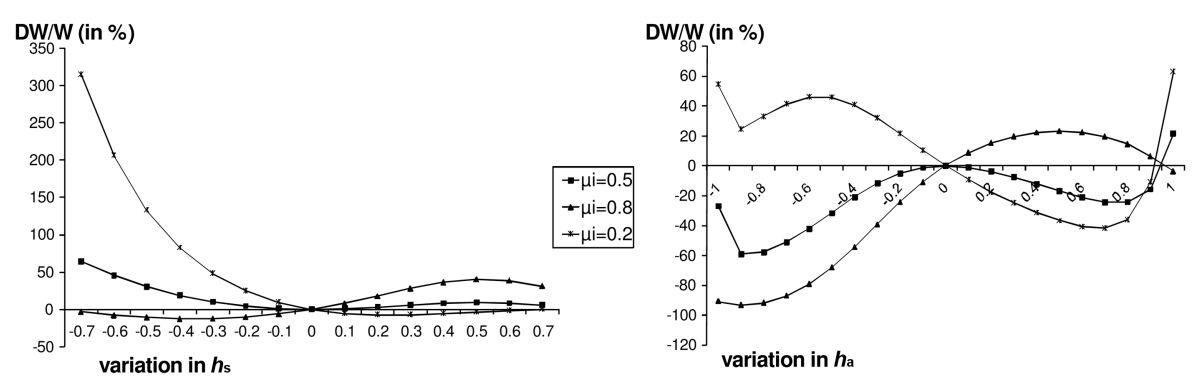
economic authorities. Besides, if the countries are structurally heterogeneous, the central bank overreacts to symmetric supply shocks when considering average variables $(A)$ if the sensibility of the demand to the interest rate $(\sigma)$ diverges between the member countries. On the contrary, monetary policy is less expansionary when the flexibility in the labor market $(a)$ is heterogeneous. Nevertheless, an appropriate weighting in its loss function of each structurally heterogeneous country could improve the monetary policy of the central bank.

Proposition 4: In case of symmetric supply shocks, the central bank of a heterogeneous monetary union can avoid leading an inappropriate monetary policy if when computing average variables, it overweights the country where the sensibility of the demand to the interest rate and where the rigidity in the labor market are the highest.

Figures $2 \mathrm{a}$ and $2 \mathrm{~b}$ show that the loss of the country (i) (and more marginally the one of the other country $(j))$ would be reduced if the central bank grants a bigger weight to that country $(i)\left(\mu_{i}>\mu_{j}\right)$ where the sensibilities of the demand and supply functions are the highest $\left(\sigma_{i}>\sigma_{j}, a_{i}>a_{j}\right)$ in the computation of average variables in its loss function $(A)$. That is also true for the degrees of openness of the countries: the centralization is beneficial only if the central bank gives a bigger weight to the country $(i)$ that is the most open $\left(b_{i}>b_{j}\right)$. Nevertheless, in this last case, the simulations show that the differential between the levels of well-being is negligible.

\section{B. Stabilization of Asymmetric Shocks}

If we assume that countries are identical from an economic point of view, the central bank should let the governments stabilize the asymmetric shocks by themselves. Indeed, after an asymmetric positive demand or supply shock, the budgetary policy must be more restrictive in the country $(i)$ affected by this shock $\left[g_{i}=-g_{j}=-1.34\left(d_{i}-d_{j}\right)\right.$ and $g_{i}=-g_{j}=-0.27\left(s_{i}-s_{j}\right)$ with identical countries]. Thus, there is generally a deflation and a decrease in activity in that country $(i)$, and on the opposite inflation and increase in activity in $(j)$. However, in case of structural heterogeneity, the centralization implies an inefficient reaction of the central bank and an increase in divergences and welfare losses in the monetary union for every country. ${ }^{8}$

First, monetary policy is restrictive if the asymmetric positive shock mostly

${ }^{8}$ In Gregoriadis et al. (2006), monetary policy does not react to asymmetric shocks when the parameters (a) or (b) are heterogeneous if the central bank relies on average variables, whereas it does in our model. 
affects the country $(i)$ which is the most open $\left(b_{i}>b_{j}\right)$, because the deflation contributes more in that context to sustain the price-competitiveness, the exports and the economic activity in that country. On the contrary, monetary policy is expansionary if the sensibility is the highest in the country $(j)$ unaffected by the shock $\left(b_{i}<b_{j}\right)$, even if this monetary activism remains quite limited in case of asymmetric demand shocks. Finally, the bias associated with centralized policymaking can always be removed if the central bank gives exactly the same weight $\left(\mu_{i}=\mu_{j}=0.5\right)$ to both countries in the computation of average variables in its loss function $(A)$. Increasing the weight of a country would only favor it much to the other country's disadvantage, in case of asymmetric demand shocks, and it would even be harmful to both countries in case of asymmetric supply shocks.

Then, in case of an asymmetric demand shock $(\bar{d})$, monetary policy is expansionary if the shock affects the country $(i)$ and if $\left(a_{i}>a_{j}\right)$, in order to compensate for the still more restrictive budgetary policy in that country, whereas it is restrictive if $\left(a_{i}<a_{j}\right)$. In the same way, in case of an asymmetric supply shock $(\bar{s})$, there can be a conflict of goals between the economic authorities. Monetary policy is very restrictive if the shock affects the country $(i)$ and if $\left(a_{i}>a_{j}\right)$, whereas the budgetary policy can even become expansionary in that country $(i)$. That monetary policy is thus very unsuited to the situation of the other country $(j)$, whose loss increases. On the contrary, monetary policy is very expansionary if $\left(a_{i}<a_{j}\right)$, and if the shock affects the country $(i)$, whose welfare decreases, whereas the budgetary policy can even become restrictive in the country $(j)$. Moreover, Figure $4 \mathrm{~b}$ shows that the bias due to centralization $(A)$ is quite ambiguous in case of an asymmetric supply shock $(\bar{s})$. On the contrary, in case of an asymmetric demand shock $(\bar{d})$, the centralization is clearly harmful to the country which has the smallest weight in the loss function of the central bank, whereas it is beneficial to the country to which the biggest weight is given (Figures 3a,b). Therefore, in case of asymmetric shocks and of a heterogeneity in the supply functions $(a)$, the central bank should give equal weights $\left(\mu_{i}=\mu_{j}=0.5\right)$ to each country in order not to harm any of them. It is the best way to minimize losses for both countries, to remove most of the bias associated with centralized policy-making.

The central bank also doesn't react to asymmetric demand shocks $(\bar{d})$ in case of heterogeneity in the transmission mechanisms of monetary policy $(\sigma)$ if it considers average variables $(A)$, whereas it does if it considers national variables $(N)$. Indeed, if the shock affects the country $(i)$ and if $\left(\sigma_{i}>\sigma_{j}\right)$, monetary policy is very restrictive, to allow a much less restrictive budgetary policy in that country $(i)$, 
whereas it is expansionary if $\left(\sigma_{i}<\sigma_{j}\right)$. Besides, in the case of an asymmetric supply shock $(\bar{s})$, there can be a conflict of goals between the economic authorities. Indeed, monetary policy is expansionary if the shock affects the country $(i)$ and if $\left(\sigma_{i}>\sigma_{j}\right)$, whereas the budgetary policy is still more restrictive in that country $(i)$ whose loss increases. On the contrary, monetary policy is restrictive if $\left(\sigma_{i}<\sigma_{j}\right)$, whereas the budgetary policy is still more expansionary in the country $(j)$ whose loss increases.

Proposition 5: In case of asymmetric shocks, the central bank of a heterogeneous monetary union should generally give equal weights to each country. Nevertheless, if the heterogeneity in the transmission mechanisms of monetary policy increases, in case of asymmetric demand shocks, the central bank should advantageously overweight the country in which the sensibility of demand to the interest rate is the highest.

Figures 3. a,b. Loss Due to Centralization for $(i)$, Asymmetric Demand Shock $(d)$
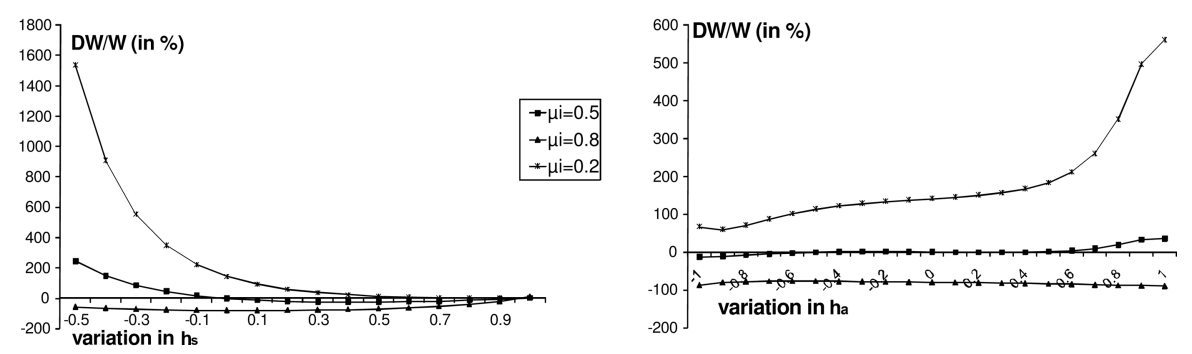

Figures 4. a,b. Loss Due to Centralization for $(i)$, Asymmetric Supply Shock $(s)$
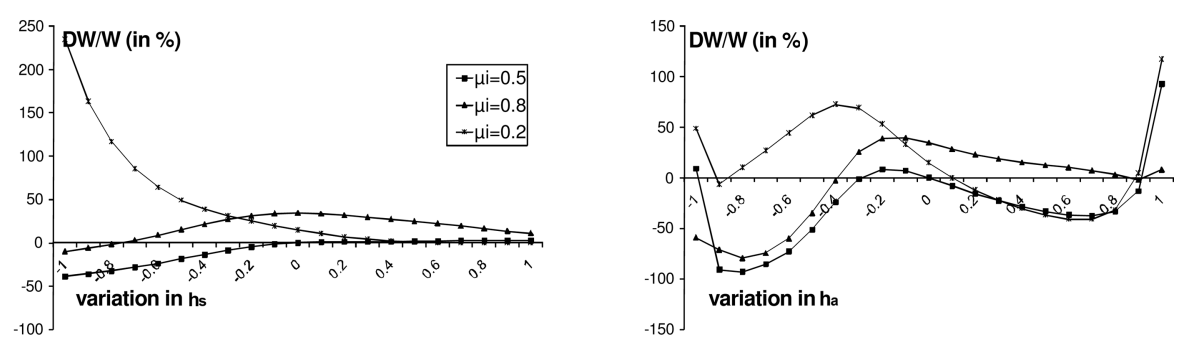
Figures $3 \mathrm{a}$ and $4 \mathrm{a}$ show that the best monetary policy is to grant equal weights $\left(\mu_{i}=\mu_{j}=0.5\right)$ to both countries if the heterogeneity in the parameter $(\sigma)$ is limited. Nevertheless, if this heterogeneity increases, in case of an asymmetric demand shock, Figure 3a shows that the cost of centralization could be reduced if the central bank overweights the country $(i)$ whose sensibility is the highest. The additional loss for the country $(j)$ would then be very limited in comparison with the important benefits for the country $(i)$.

\section{Consequences of the Heterogeneity in Preferences}

Hughes-Hallett and Weymark (2001) explore whether heterogeneity among union members could threaten the stability of the EMU. They show that the costs of membership can be significant for countries whose structure and mostly whose preferences for price stability, output growth and income redistribution deviate from those underlying the common monetary policy. In part, these costs arise because the monetary policy imposed by an independent central bank automatically constrains the use of fiscal policy by national governments, even without the introduction of any Stability Pact. In particular, as far as they conflict with a country's distributional objectives, expansionary fiscal policies cannot be used to compensate for a common monetary policy that is suboptimal and too co servative from the national perspective. Moreover, the losses associated with preferences asymmetries may be at least as large as those caused by transmission asymmetries and should not be ignored, as they have been in much of the literature. Indeed, Ullrich (2006) estimates Taylor-type reaction functions for the period 1999-2005. His econometric results then support the view that the decisions of the ECB are taken according to the developments of the whole Eurozone.

However, the maximum inflation rate and the minimum economic sentiment indicator in the enlarged Euro area seem to influence ECB decisions. In the same way, Aksoy et al. (2002) find that small countries, and those wishing to stabilize output more than their partners, have more risks to be frustrated about the interest rate decisions taken by the ECB, whatever the loss function of the central bank. However, De Grauwe and Senegas (2004) show that in a heterogeneous monetary union, when the common monetary policy transmits asymmetrically, this heterogeneity increases the need to take into account national information about inflation and unemployment in the formulation of optimal monetary policies. Nevertheless, when the relative preference of a country for the stabilization of 
economic activity to the detriment of inflation is strong, the authors show that this country would prefer the central bank to disregard national data.

In this section, we will therefore try to define the optimal monetary policy in case of discrepancies between the preferences of the countries of a monetary union. So, for this part, we will suppose the following calibration: $\sigma=0.2, b=0.4, a=3$ (see Appendix 3), $h_{a}=h_{s}=h_{b}=0, \gamma^{M}=\xi_{i}^{G}=0.5$ and $\gamma_{i}^{G}=2$. First, we will analyze the conflict between the governments regarding the economic activity and inflation goals. We will thus study the situations where the government $(j)$ gives, like the central bank, a small weight to the economic activity goal $\left(\gamma_{j}^{G}=0.5\right)$, where it weights equally inflation and economic activity $\left(\gamma_{j}^{G}=1\right)$, and where it favors the activity goal more than the partner country $\left(\gamma_{j}^{G}=4\right)$. We will also analyze the situation where the countries have different constraints regarding their fiscal policy: the government $(j)$ can have a smaller $\left(\xi_{j}^{G}=0.25\right)$ or on the contrary a higher $\left(\xi_{j}^{G}=1\right.$ or $\left.\xi_{j}^{G}=2\right)$ preference for the stabilization of public expenditures, as a higher debt level makes the constraints of the Stability and Growth Pact more binding for this country, for example.

\section{A. Stabilization of Symmetric Shocks}

The heterogeneity in the preferences of the governments is not a problem for the stabilization of symmetric demand shocks. If the countries are fully identical (structural homogeneity), the central bank can always perfectly stabilize these shocks whatever the respective preferences of the governments for the economic activity $\left(\gamma^{G}\right)$ or the variation in their public expenditures $\left(\xi^{G}\right)$.

Figures 5. a,b. Loss Due to Centralization, for Countries (i) and (j) Symmetric Supply Shock (s), $\gamma_{i}^{G}=2, \xi_{i}^{G}=0.5$
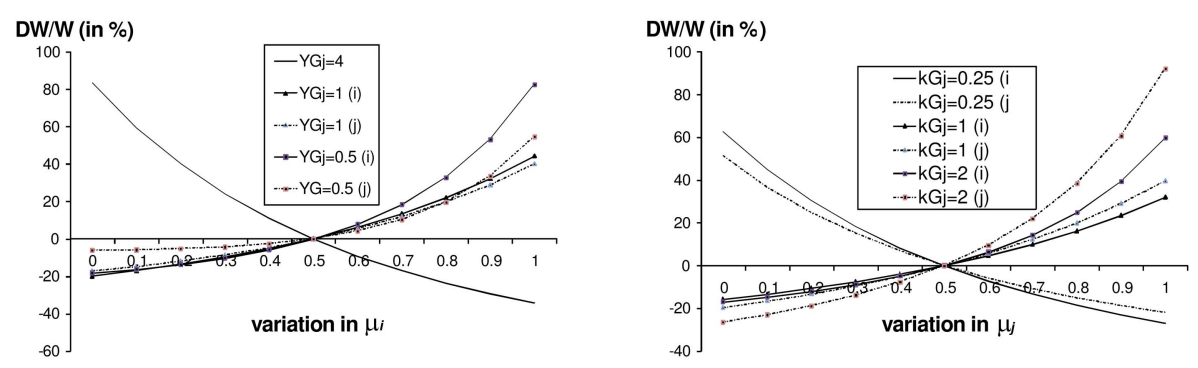
Proposition 6: In case of symmetric supply shocks, the central bank of a heterogeneous monetary union should give a bigger weight to the country which has the weakest preference for the stabilization of the economic activity, but the highest preference for the stabilization of public expenditures (Figures 5a,b). Indeed, the conflict of goals between the economic authorities is then mitigated: monetary policy is less expansionary and the budgetary policies are less restrictive. Even if this situation increases the deflation, it reduces the increase in economic activity following a positive supply shock, and the social well-being can thus be higher in both countries. However, it is the stabilization of asymmetric shocks which is, naturally, the most influenced by the heterogeneity in the preferences of the member countries of a monetary union.

\section{B. Stabilization of Asymmetric Shocks}

For the stabilization of asymmetric demand shocks $(\bar{d})$, each country, naturally, has interest in being overweighted in the computation of average variables by the central bank (Figures $6 \mathrm{a}, \mathrm{b})$. So, giving the same weight $\left(\mu_{i}=\mu_{j}=0.5\right)$ to each country allows to attain the decentralized solution $(N)$, whereas favoring one country increases the social well-being in that country to the detriment of the other. However, the central bank could eventually have interest in favoring the country which has a smaller preference for sustaining the economic activity $\left(\gamma^{G}\right)$ and/or a higher preference for stabilizing the public expenditures $\left(\xi^{G}\right)$, because the gains in social well-being of that country are then higher than the losses of the partner country. Indeed, with such a weighting, the monetary authority is more active in

Figures 6. a,b. Loss Due to Centralization, for Countries $(i)$ and $(j)$ Asymmetric Demand Shock $(\bar{d}), \gamma_{i}^{G}=2, \xi_{i}^{G}=0.5$
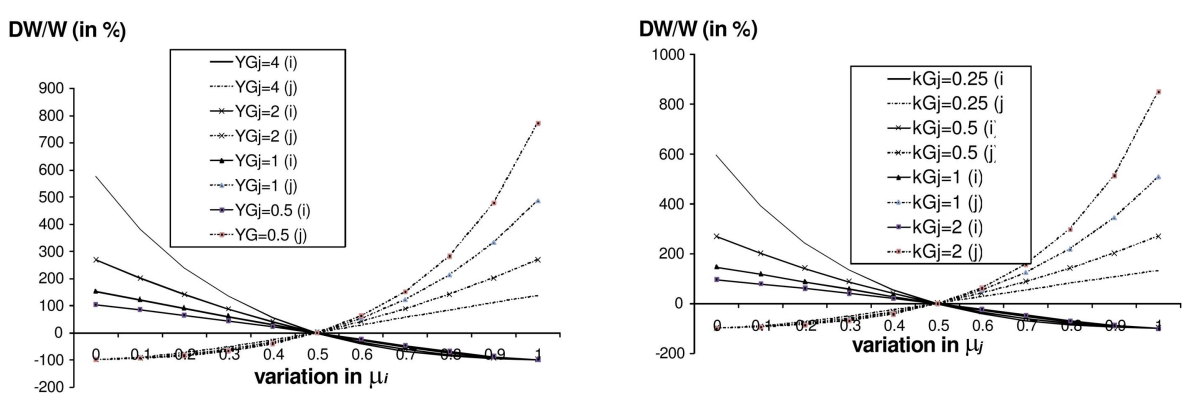
Figures 7. a,b. Loss Due to Centralization, for Countries (i) and (j) Asymmetric Supply Shock $(\bar{s}), \gamma_{i}^{G}=2, \xi_{i}^{G}=0.5$
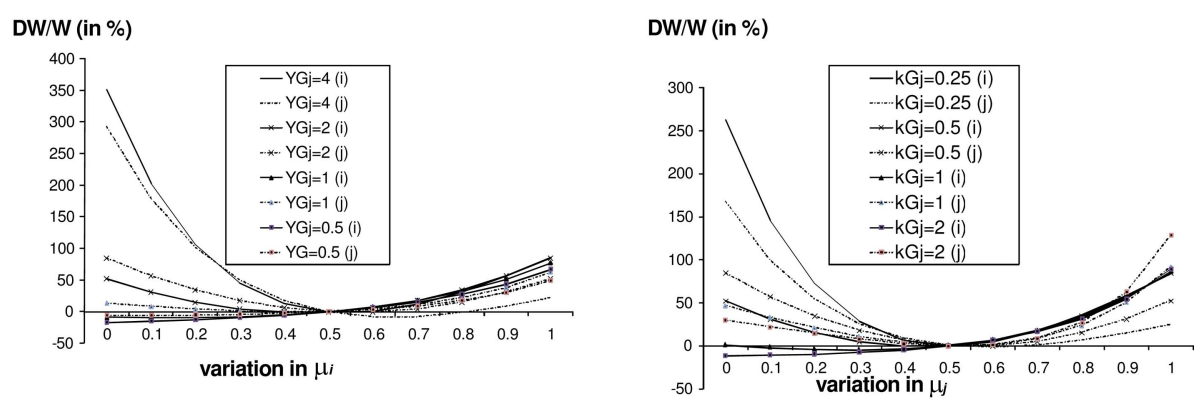

the stabilization policy, much to the benefit of the country affected by an asymmetric positive demand shock, whose budgetary policy can be less restrictive. Nevertheless, that overweighting of one country is all the more beneficial as the heterogeneity in preferences is high between the countries of a monetary union. On the contrary, it must remain very limited, and even negligible, if that heterogeneity is only weak.

Proposition 7: In case of asymmetric shocks, the central bank of a monetary union where the preferences of the countries are heterogeneous should generally give equal weights to each country. For the stabilization of asymmetric supply shocks $(\bar{s})$, the best solution is also quite always to give equal weights to both countries $\left(\mu_{i}=\mu_{j}=0.5\right)$ in the computation of average variables by the central bank (Figures $7 a, b$ ). Indeed, departing from that monetary policy could only be beneficial (and for both countries) if the preference of one government for the stabilization of the economic activity $\left(\gamma^{G}\right)$ is very weak. Then, overweighting that country could reduce the conflict of goals between the economic authorities: the monetary policy is less expansionary in the case of an asymmetric positive supply shock, and the budgetary policies can be less restrictive.

Finally, we can also note that exploiting a potential heterogeneity between the preferences of the member countries of a monetary union may induce a potential moral hazard problem. Indeed, the individual countries could be tempted to manipulate the signals regarding their objectives and their preferences to their benefit, and they may pretend to be more/less conservative to get a higher weight in the loss function of the central bank. In fact, this preference endogeneity is thus a Lucas critique, which would make unknown the precise consequences of any change in the monetary policy of the central bank. 


\section{Conclusion}

With a simple static macroeconomic model of a closed monetary union, we have tried to shed light on the optimal monetary policy of the common central bank in a monetary union. It is now widely recognized that its monetary policy can be improved by taking into account national data, beyond the simple consideration of average variables mentioned in the statutes of the European Central Bank, for example. Nevertheless, if this idea is widely admitted today, the diffi- culty is to define in which proportion the central bank of a monetary union must consider the situation of each particular country. Which weight should be given to each country, according to its structural parameters or to its preferences? The pertinent interrogation is the following: is it beneficial for the well-being of the whole monetary union that the central bank sometimes departs from a policy of equally weighting each country, and that it decides to overweight a particular country according to some criteria? The present paper investigates this interesting question, still underdeveloped in the economic literature. It shows that regarding the monetary policy intended to stabilize symmetric shocks, the central bank should give a bigger weight to the countries where the rigidity in the labor market, where the sensibility of the demand to the interest rate, and even, but more marginally, where the openness rates are the highest. Besides, to stabilize symmetric supply shocks, the central bank could advantageously overweight the country which has a smaller preference for sustaining the economic activity and which has a higher preference for stabilizing the public expenditures. On the contrary, regarding the stabilization of asymmetric shocks, the central bank has generally no reason to give a bigger weight to one country... at least as long as the heterogeneities remain limited in the monetary union with regard to asymmetric demand shocks.

These previous conclusions are thus very interesting for such a heterogeneous union as the Economic and Monetary Union in Europe. Indeed, in particular from its enlargement, the member countries of the EMU seem today to have quite different transmission mechanisms of the economic policies, openness rates, and other structural parameters, as well as different preferences for economic activity, inflation or public expenditures goals. Nevertheless, Brissimis and Skotida (2007) assume that as monetary integration advances further, structural hetero- geneities should narrow as a result of the common monetary policy and of the single financial market. So, they believe that the welfare benefits of monetary policy responding to individual countries variables may become less significant. 
Furthermore, the problem associated with a differentiated monetary policy is that it is difficult to estimate the structural parameters as well as the output-gaps for the various European countries; there is a high degree of uncertainty. Finally, taking into account structural characteristics could imply that monetary policy is accommodating the existing structural asymmetries, thus creating disincentives for reform in Euro area countries.

Received 15 October 2007, Revised 18 April 2008, Accepted 28 April 2008

\section{Appendix}

\section{A1. Inflation and Economic Activity}

By combining equations (1) and (2), we have:

$$
\begin{aligned}
\left(a_{i} a_{j}+a_{i} b_{j}+b_{i} a_{j}\right) \cdot y_{i}= & a_{i}\left(a_{j}+b_{i}+b_{j}\right) \cdot(g+d)+a_{i}\left(a_{j}+b_{j}-b_{i}\right) \cdot(\bar{g}+\bar{d}) \\
& -a_{i}\left(a_{j} \sigma_{i}+b_{j} \sigma_{i}+b_{i} \sigma_{j}\right) \cdot r-b_{i}\left(a_{i}-a_{j}\right) \cdot s+b_{i}\left(a_{i}+a_{j}\right) \cdot \bar{s} \\
\left(a_{i} a_{j}+a_{i} b_{j}+b_{i} a_{j}\right) \cdot y_{j}= & a_{j}\left(a_{i}+b_{i}+b_{j}\right) \cdot(\bar{g}+\bar{d})-a_{j}\left(a_{i}+b_{i}-b_{j}\right) \cdot(\bar{g}+\bar{d}) \\
& -a_{j}\left(a_{i} \sigma_{j}+b_{j} \sigma_{i}+b_{i} \sigma_{j}\right) \cdot r+b_{j}\left(a_{i}-a_{j}\right) \cdot s-b_{j}\left(a_{i}+a_{j}\right) \cdot \bar{s} \\
2\left(a_{i} a_{j}+a_{i} b_{j}+b_{i} a_{j}\right) \cdot y= & {\left[2 a_{i} a_{j}+\left(a_{i}+a_{j}\right)\left(b_{i}+b_{j}\right)\right] \cdot(g+d) } \\
& -\left(a_{i}+a_{j}\right)\left(b_{i}-b_{j}\right) \cdot(\bar{g}+\bar{d}-\bar{s})-\left(a_{i}-a_{j}\right)\left(b_{i}-b_{j}\right) \cdot s \\
& -\left[\left(a_{i} a_{j}+a_{i} b_{j}+a_{j} b_{j}\right) \sigma i+\left(a_{i} a_{j}+a_{j} b_{i}+a_{i} b_{i}\right) \sigma_{j}\right] \cdot r \\
\left(a_{i} a_{j}+a_{i} b_{j}+b_{i} a_{j}\right) \cdot \pi_{i}= & \left(a_{j}+b_{i}+b_{j}\right) \cdot(g+d-s)+\left(a_{j}+b_{j}-b_{i}\right) \cdot(\bar{g}+\bar{d}-\bar{s}) \\
& -\left(a_{j} \sigma_{i}+b_{j} \sigma_{i}+b_{i} \sigma_{j}\right) \cdot r \\
\left(a_{i} a_{j}+a_{i} b_{j}+b_{i} a_{j}\right) \cdot \pi_{j}= & \left(a_{i}+b_{i}+b_{j}\right) \cdot(g+d-s)-\left(a_{i}+b_{i}-b_{j}\right) \cdot(g+d-s) \\
& -\left(a_{i} \sigma_{j}+b_{i} \sigma_{j}+b_{j} \sigma_{i}\right) \cdot r \\
2\left(a_{i} a_{j}+a_{i} b_{j}+b_{i} a_{j}\right) \cdot \pi= & \left(a_{i}+a_{j}+2 b_{i}+2 b_{j}\right) \cdot(g+d-s) \\
& -\left(a_{i} \sigma_{j}+a_{j} \sigma_{i}+2 b_{i} \sigma_{j}+2 b_{j} \sigma_{i}\right) \cdot r \\
& -\left(a_{i}-a_{j}+2 b_{i}-2 b_{j}\right) \cdot(\bar{g}+\bar{d}-\bar{s}) \\
&
\end{aligned}
$$




\section{A2. Budgetary Reaction Function}

Equation (6) implies: $\frac{d L_{i}^{G}}{d g_{i}}=0=\frac{d \pi_{i}}{d g} \pi_{i}+\gamma_{i}^{G} \frac{d y_{i}}{d g_{i}} y_{i}+\xi_{i}^{G} g_{i}$. Then, we have:

$$
\begin{aligned}
& \left(\alpha_{\pi i, d 2}^{2}+\gamma_{i}^{G} \alpha_{y i, d 2}^{2}+\xi_{i}^{G}\right) g_{i} \\
& =-\left(\alpha_{\pi i, d 3} \alpha_{\pi i, d 2}+\gamma_{i}^{G} \alpha_{y i, d 3} \alpha_{y i, d 2}\right) g_{j}-\left(\alpha_{\pi i, r} \alpha_{\pi i, d 2}+\gamma_{i}^{G} \alpha_{y i, r} \alpha_{y i, d 2}\right) r \\
& -\left(\alpha_{\pi i, d} \alpha_{\pi i, d 2}+\gamma_{i}^{G} \alpha_{y i, d} \alpha_{y i, d 2}\right) d-\left(\alpha_{\pi i, \bar{d}} \alpha_{\pi i, d 2}+\gamma_{i}^{G} \alpha_{y i, \bar{d}} \alpha_{y i, d 2}\right) \bar{d} \\
& -\left(\alpha_{\pi i, s} \alpha_{\pi i, d 2}+\gamma_{i}^{G} \alpha_{y i, s} \alpha_{y i, d 2}\right) s-\left(\alpha_{\pi i, \bar{s}} \alpha_{\pi i, d 2}+\gamma_{i}^{G} \alpha_{y i, \bar{s}} \alpha_{y i, d 2}\right) \bar{s}
\end{aligned}
$$

The reaction function is symmetric for the country ( $\mathrm{j}$ ) by replacing $\alpha_{x i, d 2}$ by $\alpha_{x j, d 3}$. Thus, by replacing $\left(g_{j}\right)$ by its value, we obtain equation (7).

\section{A3. Calibration}

-Sensibility of the demand to the interest rate (parameter $\sigma$ ): A study by the ECB [Van Els et al. (2001)] gives heterogeneous results, for the negative effect during the first year of a monetary policy shock on real GDP. We can retain the following average value for the member countries of EMU: $\sigma=0.2$.

-Sensibility of the demand to the differential in inflation with the foreign country (parameter $b$ ): Parameter $\mathrm{b}$ depends on the openness rate of the economy. Moreover, the data of Eurostat give the integration of the goods market (value of the exports and of the imports of goods and services divided by twice the GDP, multiplied by 100) for the European countries in 2006. The average value for the European Union (25 countries) given by Eurostat is about $b=0.4$.

-Sensibility of the economic activity to inflation (parameter a): This sensibility can be proxied by the sacrifice ratio, that is to say the number of percentage point years of output loss required to reduce inflation by one percentage point. The annualized sacrifice ratios are estimated for example by Turner and Seghezza (1999), for the period going from 1963 (Italy) or 1974 (Netherlands) to 1997. Italy, Netherlands:1.6; Ireland:2.2; Portugal:2.4; Greece:2.5; Spain:2.6; France:3.4; Denmark:3.7; Finland:3.8; Austria:4.7; Germany:5.8; Belgium:6.5. We will thus retain the average value: $a=3$. 


\section{References}

Aksoy, Y., De Grauwe, P., Dewatcher, H. (2002), "Do Asymmetries Matter for European Monetary Policy?", European Economic Review, vol. 46, 443-469.

Angelini, P., Del Giovane, P., Siviero, S., Terlizzese, D. (2002), "Monetary Policy Rules for the Euro Area: What Role for National Information?", Bancad'Italia Temi di Discussione, $\mathrm{n}^{\circ} 457$.

Brissimis, S. N., Skotida, I. (2007), "Optimal Monetary Policy in the Euro Area in the Presence of Heterogeneity", Working Paper, n ${ }^{\circ} 62$, Bank of Greece.

Jondeau, E., Sahuc, J.-G. (2006), "Optimal Monetary Policy in an Estimated DSGE Model of Euro Area with Cross-Country Heterogeneity”, Banque de France, Notes d'Etude et de Recherche, 141, April.

Asensio, A. (2006), "Monetary and Budgetary-Fiscal Interactions in a Keynesian Heterogeneous Monetary Union", European Integration in Crisis, 10th Workshop of the Research Network Alternative Macroeconomic Policies.

Barbier-Gauchard, A., Blot, C. (2004), "Stabilization and Fiscal Policy Coordination in a Heterogeneous Monetary Union”, Document de travail, LEO, Université d'Orléans, Juin.

De Grauwe, P. (2000), "Monetary Policy in the Presence of Asymmetries", Journal of Common Market Studies, 38 (4), 593-612.

De Grauwe, P., Piskorski, T. (2001), "Union-wide Aggregates versus National Data Based Monetary Policies: Does it Matter for EMU?”, CEPR Discussion Paper, n⿳03036, November.

De Grauwe, P., Sénégas, M.-A. (2004), “Asymmetries in Monetary Policy Transmission: Some Implications for EMU and its Enlargement", Journal of Common Market Studies, 42 (4), November, 757-773.

Van Els, P. et al. (2001), "Monetary Policy Transmission in the Euro Area: What do Aggregate and National Structural Models Tell Us?", ECBWorking Paper Series, $\mathrm{n}^{\circ} 94$, December.

Gregoriadis, N., Semenescu, F., Villieu, P. (2006), "Monetary Policy and Inflation in a Heterogeneous Monetary Union”, Document de travail, LEO, Université d'Orléans, Mars.

Grimm, O., Ried, S. (2007), "Macroeconomic Policy in a Heterogeneous Monetary Union”, SFB649 Discussion Paper, 2007-028.

Gros, D., Hefeker, C. (2000), "One Size Must Fit All: National Divergences in a Monetary Union”, CES Working Paper, n⿳326, August.

Heinemann, F., Hüfner, F. (2004), "Is the View from the Eurotower Purely European? National Divergence and ECB Interest Rate Policy", Scottish Journal of Political Economy, 51 (4), September, 544-558.

Hughes-Hallett, A., Weymark, D. N. (2001), "The Cost of Heterogeneity in a Monetary Union”, Working Paper, n ${ }^{\circ} 01-\mathrm{W} 28$, Department of Economics, Vanderbilt 
University, Nashville, December.

Issing, O. (2004), "Monetary Policy Implications of Heterogeneity in a Currency Area", ECB Workshop on 13/14 December, Dinner Speech.

Penot, A. (2004), "Heterogeneity of Transmission Mechanism: a Challenge for EMU Monetary Rules, ”Working Paper, LEO, Université d'Orléans.

Turner, D., Seghezza, E. (1999), "Testing for a Common OECD Phillips Curve", Economics Department Working Papers, $\mathrm{n}^{\circ} 219$.

Ullrich, K. (2006), "The Impact of Country-Specific Economic Developments on ECB Decisions", Discussion Paper, n06-049, ZEW GmbH, June. 